\title{
ENTERING THE LIVE-STREAMING VOID AND EMERGING VICTORIOUS: TEACHING PERFORMANCE PSYCHOLOGY UNDER PRESSURE \\ Margaret S. Osborne
}

Melbourne Conservatorium of Music, The University of Melbourne, Parkville, Victoria 3010, Australia,

E-mail: mosborne@unimelb.edu.au

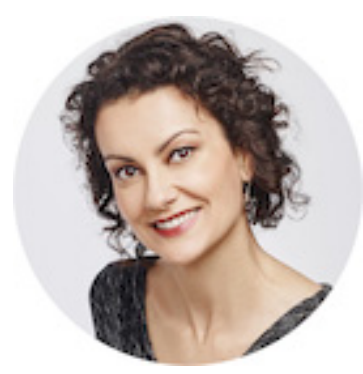

In 2019, the Melbourne Conservatorium of Music trialed a hybrid instruction method combining face-to-face teaching with simultaneous live-stream broadcast across two campuses in an undergraduate performance psychology subject. This method was fraught with technical difficulties. Yet, despite substantial instructor distress and concerns of compromised learning outcomes, students demonstrated remarkable patience, gratitude, and improvements in performance anxiety, energy regulation, focus, and resilience. This is a narrative inquiry into my experience navigating the live-streaming approach filtered through community of inquiry and self-determination theory frameworks. I reflect that within a university setting, both the teaching and technical operations staff members require generous lead time prior to the implementation of new technology to build competence and autonomy in managing unpredictable surprise factors. When this is accomplished, blended instruction can enable the staff to teach comfortably and spontaneously, providing students with unique and enriched learning experiences with access to local, national, and international experts.

KEY WORDS: performance psychology, music performance training, performance anxiety, co-streaming, online learning, blended learning

\section{INTRODUCTION}

Performance anxiety presents a substantial challenge to musicians' achievement of optimal performance, health, and well-being in educational and professional settings (Kenny \& Ackermann, 2016; Osborne \& McPherson, 2019). Evidence of psychological distress and compromised educational outcomes for music students in university settings 
(Ginsborg et al., 2012) has prompted pedagogues to introduce performance psychology teaching into conservatory curricula with promising results in traditional face-to-face (F2F) formats (Kegelaers \& Oudejans, 2020; Osborne et al., 2014; Spahn et al., 2016). As the practice of blended and fully online teaching expands, studies have begun to emerge that explore methods and student perceptions toward teaching online. Yet, there is scant documentation on effective practice for live streaming (LS) music performance classes. This paper explores this gap by reviewing the transition of a performance psychology subject offered at an Australian conservatoire from a single class fully F2F format to two classes combining $\mathrm{F} 2 \mathrm{~F}$ teaching at one campus with an interactive live-streamed videoconference link to a class at another campus. The narrative inquiry method (Clandinin et al., 2007) was chosen in order to provide a nuanced reflection of the teaching and learning features in this process. The community of inquiry (Col) model and selfdetermination theory (SDT) provide theoretical viewpoints through which to interpret the features of the educational experience, including instructor well-being. Implementation process data are presented, which include subject evaluation survey results that reveal predictable yet also surprisingly positive aspects of the student's lived experience of the live-stream instruction method. The paper ends with reflections on future performance teaching practice.

\subsection{Live-Streaming Instruction Method}

Online courses can be more beneficial than the traditional F2F delivery format. Reports of learning effectiveness for just under 1,000 undergraduate students across online and F2F courses in humanities and medicine at an Israeli university found that students in the online courses reported better understanding of course structure, better communication with course staff, higher engagement and satisfaction, and higher numbers of students viewing recorded lectures than attending F2F class (Soffer \& Nachmias, 2018). Some differences were reported by discipline, with medicine students in the online format reporting higher grades, better communication with staff and F2F class attendance, and more frequent online video viewing than humanities students (Soffer \& Nachmias, 2018). By contrast in music contexts, motivation for students to enroll in an online course may be compromised by perceptions of poor collaboration with classmates, poor teaching practice, and lack of accommodation to various student learning styles (Albert, 2015).

Blended instruction amalgamating text-based online technology and F2F instruction in synchronous and asynchronous modes is deemed to be more effective than the conventional F2F format (U.S. Department of Education, 2010). The hybrid delivery method described in this study, which simultaneously combines live-stream interactive broadcast using videoconferencing software (LS) with F2F instruction is less frequently researched. A comparative study of over 3,000 undergraduate students receiving 
instruction in either F2F, satellite broadcasting (where students are able to view and interact in real time with their instructors and classmates), or live stream (audio/video broadcast to personal computers off-campus with real-time or post-record view) at a public research university in the mid-Atlantic region of the United States indicated no difference in grade or satisfaction level between delivery modes, and supported distance education as a viable, convenient, and flexible alternative delivery mode (Abdous \& Yoshimura, 2010).

In a close approximation to the hybrid F2F/LS method employed in this study, Handler (2011) compared online only versus a co-streaming method combining simultaneous onsite and online streaming mode for university library teaching. Just over one-half of the students preferred F2F (55\%), compared to $16 \%$ co-streamed or fully online (29\%) modes. Participants rated the co-streaming mode as least satisfying compared to fully F2F or online options, citing technical troubles and differences in teaching methods across formats.

There is scant research examining the applicability and effectiveness of a hybrid instruction method in music performance contexts. Graduate music students have been found to desire hybrid formats combining F2F and online modes due to advantages of real-time interaction with peers and instructors and perception of higher quality relationships, reserving the traditional F2F mode for the development of musicianship through applied lessons and ensemble participation (Albert, 2015). Preliminary findings from a planned hybrid learning study that builds on the unique strengths of F2F and LS modes attest to a multi-faceted and multi-dimensional learning experience that enhances cultural aspects of learning song repertoire (Ruthmann \& Hebert, 2018). The Blackburn (2017) review of approaches to teaching music performance online within a higher education context made only one reference to live streaming, citing benefit alongside interviews and performances in providing students with the opportunity to network with notable professionals.

\subsection{Theoretical Perspectives}

\subsubsection{Community of Inquiry}

The Col framework involves three elements: cognitive, social, and teaching presence. These elements enable a community of learners who are guided to actively and collaboratively explore and apply new ideas in a fluid and risk-free computer-mediated environment (Garrison, 2009; Garrison et al., 2000). This was relevant for this study, given that the community was comprised of approximately one-half of the enrolled students and one-half of the two teaching staff involved in the live-streamed computer conferencing mode for $80 \%$ of the subject. 
Cognitive presence is deemed the most basic ingredient for success. It considers the ability of students to construct meaning through sustained communication (Garrison et al., 2000). It is particularly noteworthy when the medium of communication changes, which in the case of the current study changed from three years of full F2F delivery to a combination of in-person and LS instruction. As stated in Garrison (2009), in order to develop cognitive presence, "learners are tasked with a problem or issue and, through iteration between discourse and reflection (public and private worlds), construct meaning and confirm understanding" (p. 353).

The primary purpose of social presence is to support the critical thinking, ideation, and information exchange tasks involved in cognitive presence. Social presence is indicated by open and purposeful communication in a risk-free environment, where students feel confident to express their ideas, personalities, and emotions (Garrison, 2009). The development of a socially trusting environment in this community of students is noteworthy in this peak performance subject case study, given the anxiety and self-efficacy vulnerabilities that can be triggered by the need to perform in front of others.

Teaching presence binds the two other aspects together through subject curriculum design and organization, constructive discourse facilitation, and direct instruction to inform and resolve issues. Meaningful online learning is most likely to occur when teachers assume the role of facilitator rather than instructor (Lowenthal \& Parscal, 2008). Teaching presence influences student satisfaction and perceptions of perceived learning (Lowenthal \& Lowenthal, 2009).

In a rare investigation of an instructional approach approximating the current hybrid method, Szeto (2015) drew explicitly from the Col framework using blended synchronous online videoconferencing and F2F teaching. A computer-aided engineering drawing course with 28 students involved an instructor teaching theory and performing hands-on demonstrations with students divided into online and F2F groups participating in learning activities. The technological infrastructure consisted of regular computer and network facilities with desktop videoconferencing devices and projectors available in university teaching venues without the bespoke technical configuration. High-quality videoconference facilities were vital in mediating the blended synchronous environment for participants. At the outset, teaching, social, and cognitive presence were assumed to play an equal role in shaping the educational experience. Yet, the key role of teaching presence in establishing and sustaining a Col (Garrison et al., 2010) was affirmed. Teaching presence dominated the attainment of intended learning outcomes in this blended environment via the perception of instructor as performer (Szeto, 2015). This fulfilled a leadership role that was perceived to be effective and meaningful through enhanced clarity and comprehensive coverage of the concepts by virtue of the preparation for online delivery. F2F students 
noted that the steady, slow method of instruction provided extraordinary depth compared to normal class teaching, although increased repetition tended to make the experience feel a little unnatural.

\subsubsection{Self-Determination Theory}

Self-determination theory is another relevant framework through which to view the student and teacher educational experience in this study. This theory attests to the idea that people who perceive their basic psychological needs are satisfied tend to be intrinsically motivated. These basic needs include the following: competence (the desire to feel effective in carrying out duties), relatedness (the need to feel connected to others, to be a group member, and develop close and intimate relationships with others), and autonomy (volition, choice, and sense of personal control in executing tasks). When these three needs are satisfied, a person is more likely to seek out new challenges and opportunities to learn and to display mastery of their environment, even in the absence of external rewards. Associated benefits in the workplace include positive psychological adjustment and successful performance, particularly when orientations are geared toward autonomy and support (Baard et al., 2004).

Investigations of SDT in educational contexts are typically geared toward the psychological needs of students, where student perceptions of autonomy and competence have the greatest influence on satisfying and productive learning experiences (Jang et al., 2010; Taylor \& Ntoumanis, 2007). In music settings, competence correlates most highly with the desire to master challenging tasks, and satisfaction of all three psychological needs facilitates autonomous motivation and increased practice frequency, quality, and preference for challenge (Evans \& Bonneville-Roussy, 2016). The psychological needs of teachers have been less frequently investigated but are equally important in the reciprocal educational experience between teacher and student (Taylor \& Ntoumanis, 2007). Similar to students, teachers' perceptions of autonomy support from principals, educational systems, and policies are significantly associated with the satisfaction of their own basic needs (Klassen et al., 2012). Teachers' emotions and autonomous motivation influence students' emotions and motivation, with relatedness being the underemphasized conduit through which these take place. Connecting with students is a critical component of teachers' need for relatedness, which in turn increases their engagement and positive emotion and lowers negative emotions (Klassen et al., 2012).

\section{THE PRESENT STUDY}

Using the developed background context, I present a narrative inquiry into my experience as teacher/subject coordinator using the hybrid F2F/LS method. The task was the transfer of an undergraduate performance psychology subject from a fully F2F format at one 
campus (which historically had incorporated a small amount of live streaming from national and international subject matter experts to enhance the depth of content delivery) to an $80 \%$ hybrid format for two classes across two campuses to overcome distance restrictions to student enrollment. Following the Szeto (2015) conclusion that instructional effects of the three Col presences were largely context specific, I was intrigued to see how similar the findings would be when considering my own hybrid subject delivery experience through the Col lens. What if, despite the best of intentions, you're unexpectedly placed in an F2F/LS teaching model that is poorly executed and seems more akin to emergency remote learning?

\subsection{Teaching Context}

This study was conducted in Australia's second oldest university, which incorporates the oldest and largest music conservatorium in the country. The university conducts learning and teaching, research, and engagement at seven campuses across its state. At the start of 2019 the conservatorium moved the majority of the staff, teaching, and performance activities from the main city campus to a new bespoke building on the performing arts campus, $4 \mathrm{~km}$ (or a 20-30 minute tram ride) from the main Melbourne city campus. With the increase in streaming technologies being installed at the university to meet the growing demand for synchronous and asynchronous online education, this was seen as an opportunity to continue to engage with and support music students across both campuses. The university has a distinctive curriculum that provides students with considerable flexibility to choose subjects beyond the core discipline of their degree (known as "breadth" subjects). The streaming technology was desirable since it enabled the conservatorium to continue teaching performance content to students from other disciplines (including liberal arts, biomedicine, commerce, architecture and design, and science) at the university's main city campus.

The move of nearly all of the conservatorium teaching and performance activities from the main campus to the new campus for teaching in Semester 1 in 2019 facilitated an experiment in extending the reach of teaching through a hybrid F2F/LS instructional approach. These sessions were taught across two campuses simultaneously, where students could view and interact in real time with their instructors and classmates. The same session was taught to students situated in two classroom groups (one at each campus), with two instructors (one at each campus), who either led the instruction or facilitated content delivery in the session at any one time. Students could direct questions to either instructor in real time, and converse with their student cohort in the other location in guided question and answer sessions facilitated as appropriate to the schedule of content delivery by the instructor. This vision of a collaborative learning space capable of encouraging meaningful social and cognitive engagement was anticipated to maximize the 
reach of the subject by delivering to music-specific (new campus) and breadth domains (main campus).

\subsection{Subject Rationale}

In 2016, my colleague and I developed a new performance psychology subject, Peak Performance under Pressure, drawing from the epistemology of performance psychology defined as "...the study and application of psychological principles of human performance to help people consistently perform in the upper range of their capabilities and more thoroughly enjoy the performance process" (APA Division 47 Practice Committee, Portenga et al, 2017, p. 52). In the spirit of iterative cycles of teaching design (e.g., Reeves, 2006), this subject was developed by the author and colleague (co-teacher) to address the problem of observed difficulties of tertiary music students in coping with performance anxiety when preparing for and executing high-pressure performances.

The subject aim is for students to correctly understand and apply the latest evidence in general principles of human performance, as well as applications that may be more specifically aligned to their performance area of interest. Hence, there is a dominant active and self-referential component to the tasks, assessments, and tools. Students are expected to engage in a degree of self-directed behavior modification (Watson \& Tharp, 2014) in order to understand and experience firsthand the challenges and breakthroughs in applying strategies in the hope of maximizing performance potential in themselves, and if necessary teaching this understanding to others (a pertinent consideration given many tertiary-educated musicians end up working as music educators).

The instructional and assessment methods were chosen to increase "learntime" (Goodyear, 2015) through the principles of self-regulated learning. In a constructive alignment of the subject's performance enhancement content, learning outcomes (see Section 2.4, especially learning outcomes 4 and 5), tasks, and assessments, students construct knowledge by actively planning, performing, monitoring, and regulating learning processes (Zimmerman, 2011). They learn to set effective goals and orient toward them, and to engage in "the strategies used to achieve goals; the management of resources; the effort exerted; reactions to external feedback; the products produced" (Nicol \& Macfarlane-Dick, 2006, p. 199). The idiographic and synchronous tasks and assessments are demonstrated in the first assignment through students specifying their individualized performance goal. They are given feedback to refine their goal before progressively and systematically applying the strategies throughout the semester in selfreflective journals. These results are integrated into their final assignment: a critical appraisal of the literature and self-reflective learning journal on effectiveness of performance strategies. The progressive nature of assessment feedback enables both 
students and staff to be informed across the semester about requirements, expectations, and progress of learning across a variety of formats (Harris, 2005).

Over three years of F2F delivery, the subject received excellent student evaluation survey ratings with a mean of 4.02 on a scale of strongly disagree (1) to strongly agree (5), with the highest ratings given to learning "new ideas, approaches and/or skills," and applying "knowledge to practice." Students responded positively to the interactive lectures and the practical and applicable nature of the subject material. The integration and breadth of scientific research to explain applied performance concepts spurred further thinking outside the core course material. The majority of students agreed that the best aspects of the course were that the practical strategies and individualized skills assessments not only helped their specific performance task but also helped them manage emotional stress in other aspects of their lives.

The social context of performing in front of others was deemed a necessary learning environment for this subject, since this raises self-presentation and negative evaluation fears, which are some of the main triggers for performance choking (Mesagno et al., 2016; Osborne \& Franklin, 2002). Adopting a wider theoretical lens, according to SDT (Ryan \& Deci, 2002), the social context is likely to enable students' capacity to build internalized motivation for learning and mastery, since they are provided with the opportunity (alongside the group presentation project) to develop performance competencies that are valued by others (e.g., teacher and peers). Competence and relatedness are two of the three psychological needs that allow learners to develop in a healthy and optimal way (McPherson et al., 2016). Therefore, F2F instruction was initially chosen as the preferred delivery method since we believed learning outcomes would likely be diminished in an entirely non-contact/online delivery course format.

Autonomy, the third basic psychological need, is a key design feature that resonates through teaching and assessment tasks. Students who choose their own performance goal are likely to find the tasks more personally meaningful, aligning with their personal needs and interests, and in the case of the group performance assignment, enriching their social and learning networks (Goodyear, 2015). In this way, active, self-regulated learning is encouraged and supported by high-quality feedback, which clarifies good performance (goals, strategies, and performance criteria), develops self-assessment and reflection of strengths and areas for improvement, and encourages peer/teacher dialogue and opportunities to close the gap between current/desired performances. It also provides information that can be used by staff to modify upcoming lectures to address nuanced needs of the yearly student cohort (Harris, 2005; Nicol \& Macfarlane-Dick, 2006). 


\subsection{Student Cohort}

There were 43 students enrolled in the subject Peak Performance under Pressure, of which 25 were music students enrolled to take the subject at the new campus (using music performance as their performance activity to work on) and 18 were breadth students enrolled to take the subject at the main campus. Breadth students were non-music specialist students who learned to apply performance anxiety management and confidence building techniques to other performance activities such as public speaking, high-performance sports, and performing arts activities such as drama.

\subsection{Schedule and Learning Activities}

The subject was delivered on campus in the second semester of the 2019 academic year through 12 weeks of 2-hour weekly classes scheduled on Mondays. The subject was delivered by two instructors: one instructor (me) was a psychologist specializing in performance science who focused on theoretical and research literature, and the other instructor was a senior music performance teaching faculty colleague and professional musician, who translated the literature into practical examples and guided student activities during the lectures. Additional guest lecturers were involved in four classes. See Table 1 for the summary schedule.

TABLE 1: Peak performance under pressure summary subject schedule

\begin{tabular}{|lll|}
\hline $\begin{array}{l}\text { Scheduled } \\
\text { Week }\end{array}$ & Method & Time Period \\
1-2; 6-10; 12 & Live-streamed lectorials across campus & $\begin{array}{l}\text { July 29 to October 21 } \\
\text { (weeks 1-12) }\end{array}$ \\
3 and 5 & $\begin{array}{l}\text { Guest lecturer streamed from the United } \\
\text { States to both campuses }\end{array}$ & August 12 and 26 \\
4 & $\begin{array}{l}\text { Non-streamed practical class; Assessment 1 } \\
\text { due }\end{array}$ & August 19 \\
11 & $\begin{array}{l}\text { Non-streamed group performance } \\
\text { presentations; Assessment 2 due }\end{array}$ & October 14 \\
\hline
\end{tabular}

Classes were conceived as "lectorials," blending didactic lecture format where the main points of the material are explained in relation to core readings and additional research literature, with whole group, peer-to-peer, and small group interactive activities that elaborate on, and encourage self-reflection of, students' own practice and experiences. Class activities involved guided practice in applying techniques discussed in the lectures, coupled with mini-performances and other simulated performance tasks that attempt to 
address the performance needs of the student demographic of the group. Learning outcomes required students to:

1. Explain the main theories of peak performance;

2. Describe how to develop consistent skill execution and positive performance experiences;

3. Recognize and prevent the cognitive, emotional, behavioral, and psychophysiological inhibitors of consistent, excellent performance;

4. Develop the mental and emotional knowledge, skills, and abilities required for achieving one's full potential in a selected performance domain; and

5. Apply evidence-based strategies to facilitate performance in high-pressure situations.

There were three assessment tasks:

1. Self-assessment incorporating results of psychological performance skills inventory, in which a results profile informs the selection of appropriate strategies to practice and is reflected on in self-reflective journals and written assignments across the subject;

2. Contribution to small group presentation, or a public music performance and selfreflection that interrogates the unique challenges of achieving peak performance in a particular performance domain, which includes a written summary submitted on day of presentation; and

3. A critical appraisal of the literature and self-reflection on effectiveness of performance strategies used during the semester, including results of the second skills inventory and self-reflective journal as appendices.

\subsection{Infrastructure and Equipment}

\subsubsection{Venues}

The venues included two teaching spaces, referred to here as Hall (new campus) and Room (main campus). At the time, Hall was the only teaching space at the new campus fitted with streaming technology and music performance space capability; Room was a smaller multi-function classroom with central university lecture capture hardware newly installed (for 2019 cross-campus streaming).

\subsubsection{Equipment}

The streaming platform Zoom was accessed via the presenter's university account. Audio conferencing hardware options were set through Zoom, including microphone, speakers, 
and cameras operating through multiple Extron MediaPort 200 options, which varied across venues (microphone selection options: Same as System, Extron MediaPort200; MacBook Pro Microphone; speaker selection options: Same as System, DisplayPort Extron HDMI, Extron MediaPort200, Extron MediaPort200\#1, MacBook Pro Speakers). For two weeks, an external presenter from the United States used Skype to teach, which was streamed across campus using Zoom via Extron MediaPort 200. Lecture slides and audio were automatically recorded for timetabled classes using Echo360 and uploaded to the Learning Management System within a few hours of the lecture ending. Two different computers were used in the two venues, both running iOS software: a Mac desktop in Room, and a MacBook Pro laptop at Hall, which was reimaged one business day before teaching started (resulting in slightly different microphone/speaker options to those that my colleague and I were trained on in the lead up to teaching).

\subsection{PREPARATION TO BUILD COMPETENCE}

In 2019, Semester 1 was the first trial of cross-campus live streaming for Melbourne Conservatorium of Music (MCM) subjects. Having observed the difficulties colleagues had experienced implementing this method, three months in advance of our first lecture the MCM online teaching and learning specialist guided my co-instructor and me in operating the audio-visual equipment and delivering content across both venues. Two written guides were developed, along with a narrated 2-minute instructional video. One of the guides, a 14 page, seven step faculty-specific "Streaming How-to Zoom Guide" with dot point instructions and images developed for the three teaching venues covered the following steps: 1, logging into Zoom; 2, starting the Zoom session as lecturer or tutor/guest lecturer; 3 , connecting the camera and testing audio; 4, sharing a presentation; 5 , managing participants; 6, recording the session; and 7, ending the session. Point 4 of the instructional guide recommended that instructors become familiar with the rooms prior to giving any presentation. In order to develop competence in the technology, our journey entering the LS void with $T$ as the first lecture was signposted by the practice challenges summarized in Table 2. Despite these challenges, learning environments and infrastructure support staff assured us that the issues raised in Semester 1 would be rectified for Semester 2. 
TABLE 2: Preparatory timeline

\section{Countdown \\ to $T$ = First Lecture \\ Performance Practice and Challenges \\ (Monday)}

$T$ minus 3

months

One hour of preparation time scheduled into the faculty room teaching timetable prior to the scheduled lecture start time of $10 \mathrm{a} . \mathrm{m}$. in both venues (Hall and Room) to ensure my co-instructor and I had sufficient time to start up and test the live-stream connection prior to commencement of class.

$T$ minus 8 weeks

$T$ minus 6 weeks

$T$ minus 2 weeks

$T$ minus 5-7 days

$T$ minus 2 days (Thursday)

I met with the online learning and educational technology faculty member specialist to learn Zoom and PowerPoint presentation share file orientations away from the venues.

Streaming practice in the Hall and Room with my co-instructor and the online learning and educational technology faculty specialist.

My co-instructor and I practiced the whole process from startup to shutdown, twice. A number of difficulties were still evident, captured in personal communication from my teaching colleague, D. Immel (July 15, 2019)

"Microphone pick-up from Hall to Parkville's Room ONLY worked if we chose the "laptop mic" option. Extron 200 system did not pick up sound and I could not be

heard in Room. Video worked from the 'FaceTime' video option. But then stopped working when we muted or paused our Zoom session. The FaceTime camera

did not work after that. The Extron camera did operate, but only shows stage (we need Room presenter to see the podium and screen, and not the stage)."

Notably, our confidence in navigating the equipment on our own was uncertain, knowing that a new piece of hardware was yet to be installed before $T$.

My co-instructor and I practice the whole process from startup to shutdown, twice. At this point, we felt reasonably competent in operating the equipment such that we could focus on our teaching content. To reach this level of competence required 14 hours of face-to-face academic teaching time (7 hours each), plus hours of technical support officer time.

At 2 p.m. on the second business day before $T$ (day 1 of Semester 2), the 1 hour pre-class streaming setup time scheduled in the Hall three months prior had been gazumped by another faculty subject without notifying either myself as subject coordinator or my co-instructor. A flurry of phone calls and emails ensued, with access to the Hall reinstated at 6:35 p.m. Given that the extent of our preparations had yielded only a moderate degree of confidence in navigating the live-stream technology, the thought that the preparatory hour would be taken away from us yielded another level of immediate, heightened psychological distress prior to teaching, which had nothing to do with what we were teaching. 


\section{OUTCOMES}

\subsection{Implementation Challenges (the "Void")}

Despite the two instructional documents and video provided by the learning environment and online teaching specialists, hardware incompatibility and software issues leading up to and beyond the first day of lecture delivery provided a number of pain points to hijack a successful educational experience. The classes for weeks 1 and 2 were delivered with significant streaming connectivity issues. The impact of these issues and their negative influence on my mental health and well-being and that of my co-instructor were substantial, which are synthesized in the following quotes taken from two emails sent on the evening of the second class:

"Intermittent and unpredictable hardware faults, e.g., audio and/or visual Zoom streaming drop outs from one location to another... We cannot continue in this method, even to end of semester if not fixed. We (faculty, teaching staff) look like fools, which we (teaching staff) wear in our SES results, with performance development review impacts on our performance over which we have no control" (M. S. Osborne, August 5, 2019, 6:49 p.m.).

"I can see no other way of preserving our reputation and pedagogical integrity. While this will result in a huge loss of revenue, it may keep our staff healthy enough to succeed with (cancelling the subject) delivery of their remaining teaching requirements" (D. Immel, August 5, 2019, 9:10 p.m.).

As the timing of the emails indicates, these technology issues were taking significant time out of "regular" business hours, and are testament to compromised work/life balance and staff occupational health and safety needs. These emails were sent to the Faculty Head of Infrastructure and Operations, the central university infrastructure services engineer responsible for collaboration endpoints, and forwarded to coordinators of four other subjects who were also experiencing the same technology issues. Despite the hard work, forethought, training, support, and contingency planning of the music online learning and educational technology specialist, problems were as bad if not worse than Semester 1 , perhaps due to our expectation of a seamless experience.

After this low point, it was revealed that a crucial software update had not been undertaken in the Room, which was then completed prior to the lecture scheduled for week 3 . From this point, teaching resumed and continued in a fairly seamless manner until week 7 . On the Friday of week 6, an opera had been staged in the Hall. In order to stage the opera, the lectern housing the computer and audio-visual equipment (pictured on the right-hand side in Fig. 1), had been completely removed from the stage. The performance had been held, and no infrastructure staff were scheduled in the building over the weekend to 
rearrange the lectern to the usual position on stage prior to the 10 a.m. Monday class on week 7. My co-instructor arrived at the Hall at 9 a.m. on Monday to discover the lectern had been removed and was sitting behind the stage. Despite being a senior experienced lecturer and professional musician, he felt this was an unbelievably stressful event and a "return to ground zero," undoing the tremendous amount of time and effort expended to gain tentative confidence in the streaming technology, which was then stripped away. Remarkably, the relevant learning environment and infrastructure staff were contacted and were able to attend the venue to connect the lectern with only 10 minutes delay to the start of the lecture.

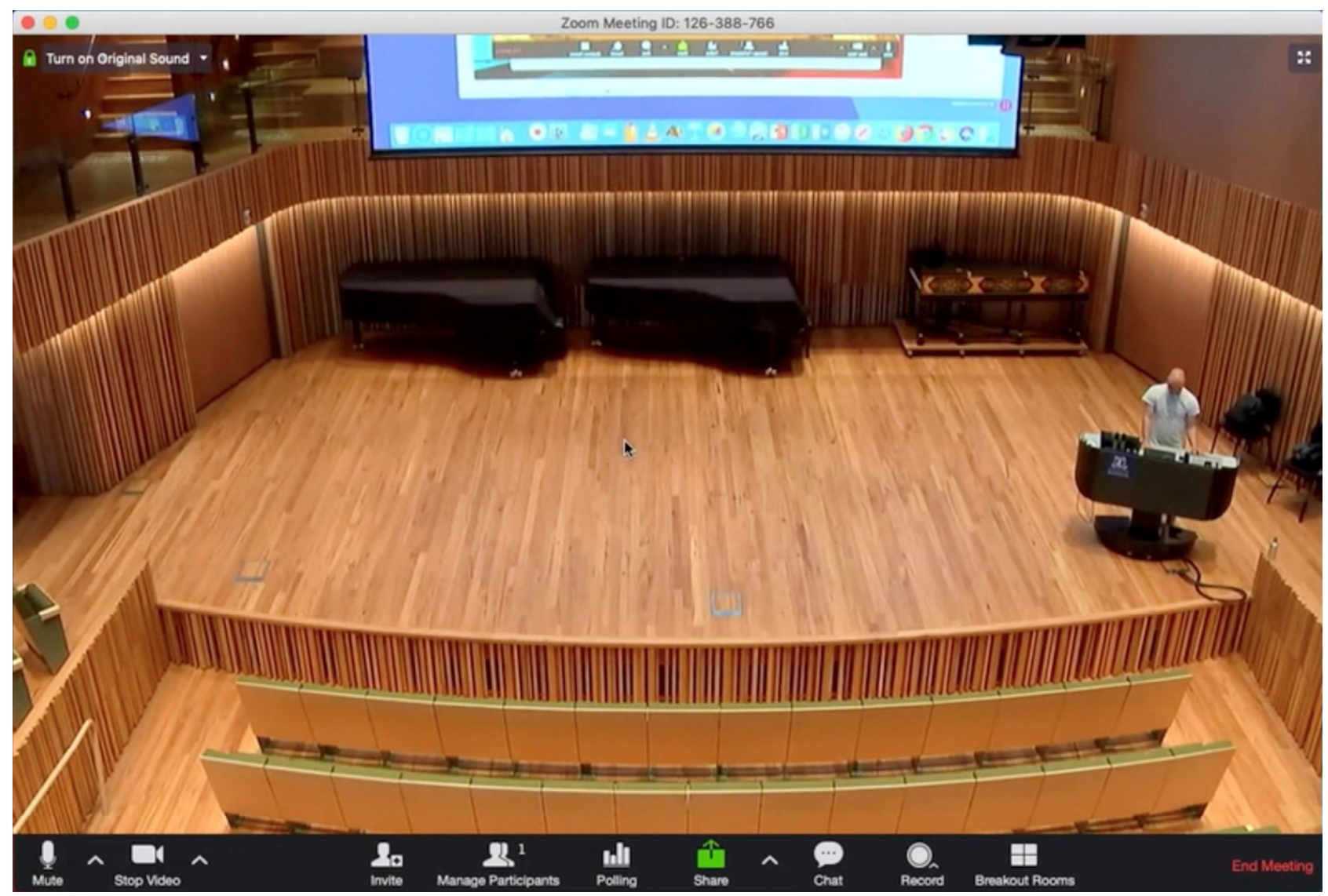

FIG. 1: Hall stage, screen, and lectern setup (Zoom image taken from the instructional video)

\subsection{Student Experience}

As per usual protocol, in the final weeks of teaching the university administered a 10-item subject experience survey (SES) for all students enrolled in classes. Items were answered on a 5-point Likert scale of 1 (strongly disagree) to 5 (strongly agree). Despite our deep concerns that the prolific difficulties with the LS technology would have compromised ratings of their experience, this seemed not to be the case. We received strong positive 
ratings to learning "new ideas, approaches and/or skills" (main campus: $M=4.57$; $\mathrm{SD}=$ $0.45 ; n=12$ ), and applying "knowledge to practice" (new campus: $M=4.86$; SD $=0.36$ ), with mean ratings for the item "this subject has been well taught" at the main campus $M=$ $4.42(S D=0.90)$ and new campus $M=4.07(S D=1.0)$. Overall, the mean values across all 10 items for both campuses were actually higher than the previous three years of F2F teaching combined, as shown in Fig. 2.

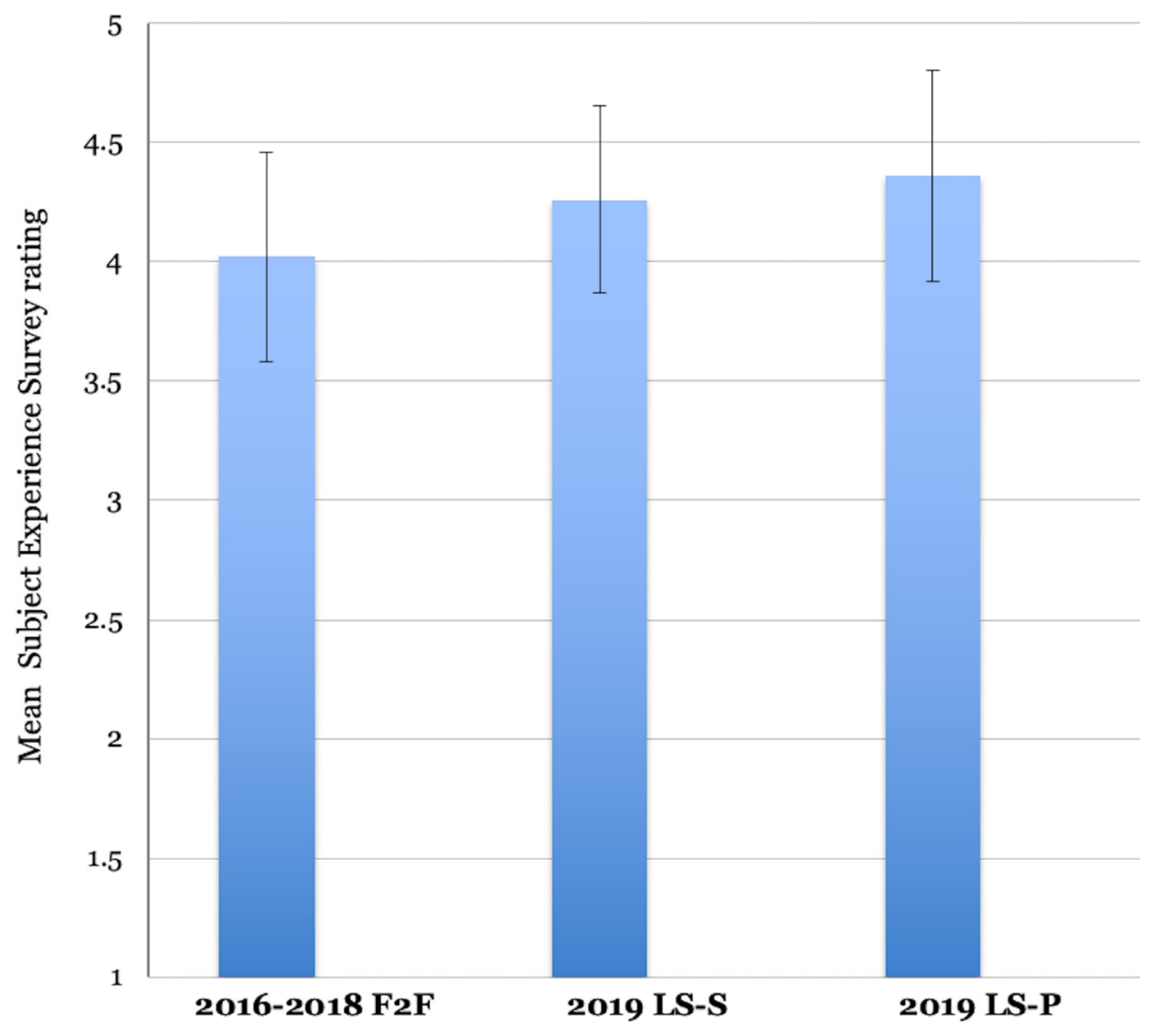

FIG. 2: Subject experience survey rating by year and instructional method: F2F face to face; LS-S live streaming (new campus); LS-P live streaming (main campus)

\subsubsection{Thematic Analyses}

Two open-ended questions in the SES asked students to consider the best aspects of the subject, and what could be improved. Under improvements, there was a marked difference in the frequency of comments referencing technical and streaming issues: $17 \%$ at the new campus compared to $60 \%$ at the main campus. This is somewhat surprising, given that the mean satisfaction rating at the main campus was slightly higher than the new campus (Fig. 2). Intriguingly, one of the best aspects was cited as great use of teaching technology, for example, live streaming the U.S. performance psychology expert. The responses were coded as follows: 
- Col model: Responses were coded according to the Garrison (2009) elements and indicators, with frequencies shown in Table 3.

- Self-determination Theory: Following Klassen et al. (2012), open-ended responses were also coded according to the articulation of the three basic psychological needs (Table 4).

TABLE 3: Subject experience survey open-ended responses coded to Col model (percentage of total responses and themes)

\begin{tabular}{|c|c|c|}
\hline Element & Best Aspects & Improvements \\
\hline & $32 \%$ & \\
\hline & - Welcoming, safe space & $14 \%$ \\
\hline $\begin{array}{l}\text { Social } \\
\text { presence }\end{array}$ & $\begin{array}{l}\text { strategies in } \\
\text { performance }\end{array}$ & - Group assignment (resistance to group \\
\hline & $\begin{array}{l}\text { - Interactivity between } \\
\text { students and instructors }\end{array}$ & \\
\hline & $77 \%$ & \\
\hline & $\begin{array}{l}\text { - Relevant, high-quality } \\
\text { practical content }\end{array}$ & \\
\hline Cognitive & essential to performance & $27 \%$ \\
\hline presence & Clait & - Specific to performance anxiety experience \\
\hline & - Individually tailored & \\
\hline & $\begin{array}{l}\text { - Strategies for life within } \\
\text { and beyond the subject }\end{array}$ & \\
\hline & $45 \%$ & $82 \%$ \\
\hline & $\begin{array}{l}\text { - Well taught, entertaining, } \\
\text { engaging, and lively } \\
\text { lecture format }\end{array}$ & - Streaming technology issues taking away \\
\hline Teaching & - Instructor expertise & and slides online at a later time \\
\hline & - Two instructors & - Group assignment instructions \\
\hline & - Separate music and non- & - Split across two campuses \\
\hline & - Well-coordinated & - More time for performance \\
\hline
\end{tabular}

Responses combine both campuses: new $n=12$; main $n=10$. 
TABLE 4: Subject experience survey open-ended responses coded to expression of basic psychological needs (percentage of total responses and themes)

\begin{tabular}{|c|c|c|}
\hline Element & Best Aspects & Improvements \\
\hline & $45 \%$ & \\
\hline Autonomy & $\begin{array}{l}\text { - Encouraged self-knowledge } \\
\text { through self-discovery }\end{array}$ & $0 \%$ \\
\hline & $\begin{array}{l}\text { - Individualized strategies as } \\
\text { performer and in rest of life }\end{array}$ & \\
\hline & $45 \%$ & \\
\hline & $\begin{array}{l}\text { - Learning together in a safe } \\
\text { environment }\end{array}$ & $32 \%$ \\
\hline Relatedness & $\begin{array}{l}\text { - Interactive, exploring peer } \\
\text { experiences }\end{array}$ & $\begin{array}{l}\text { - Technical difficulties impeded } \\
\text { relationship with instructor at } \\
\text { other site }\end{array}$ \\
\hline & $\begin{array}{l}\text { - Connection to subject matter } \\
\text { experts via live stream }\end{array}$ & \\
\hline & $95 \%$ & \\
\hline & - Instructor expertise & $82 \%$ \\
\hline Comnotonco & - Performance practice encouraged & - Streaming technology \\
\hline & strategies & - Unclear group assessment \\
\hline & $\begin{array}{l}\text { - Clear, interesting, and stimulating } \\
\text { content }\end{array}$ & \\
\hline
\end{tabular}

Responses combine both campuses: new $n=12$; main $n=10$.

\section{REFLECTION}

This paper discusses the curious and unexpected scenario that my colleague and I found ourselves in, which was to teach a subject on the topic of peak performance under pressure while simultaneously having our capacity to do that compromised via prolific difficulties with unreliable LS technology, thereby putting us in the position of needing ourselves to execute and model peak performance under pressure as instructors. The implementation process contradicted the first and fundamental model taught in the subject, that is, that optimal performance is a synergy of technical competence and physical and psychological well-being (Williamon, 2004). In the first instance, we instruct students to ensure technical mastery; otherwise, psychological well-being can be compromised through increased stress and anxiety. 
Our experience of a "lift and shift" of the subject's F2F teaching approach and content into a hybrid F2F/LS instruction mode across two campuses involved an extraordinary number of training hours in addition to our normal duties. Ongoing complex problem solving for two campus learning environment infrastructure support teams encroached into the F2F teaching time of the subject and impeded potential financial efficiency gains of streaming. Excessive time spent on failed attempts to ensure audio-visual technical security meant that attention to actual teaching content was substantially compromised. Additionally, our work/life balance was severely compromised, which impacted our well-being.

Our ultimate goal for teaching music performance skills is to enable music students to experience a sense of creative flow in their playing in whatever performance context they find themselves in. As pedagogues, we were fundamentally concerned that our subject's goal to effectively teach performance psychology concepts and strategies to enable creative flow was compromised by the unpredictable technical milieu. Yet, in spite of this, students reported that we did meet the challenge of constructing authentic performance psychology instruction in real time. Upon reflection, I suspect this outcome was facilitated by two of the 12 classes being conducted offline. We still relied, to some degree, on the F2F method to enable the practice of strategies to support peak performance under pressure. Overall, we concluded that the constructivist learning approach embedded in the subject's curriculum design was able to withstand some of the technological challenges to support an authentic learning experience and transfer of knowledge to the activity of music performance (Johnson \& Altowairiki, 2017).

The high percentage of students endorsing cognitive presence indicators under "best aspects" of the subject (Table 3 ) speaks to the robust constructivist curriculum design incorporating self-directed and self-regulated learning principles. Each student completed a self-assessment of 21 psychological performance skills at the start of the subject. This guided the selection of individualized strategies for each student to practice throughout the subject. Two of the three areas-energy regulation and self-talk-were the same for all students since they are key variables that most people, at some time in their performance histories, typically have difficulty with when learning to perform their best under pressure. These two areas acted as a bridge between the student's public and private worlds (Garrison, 2009). The third strategy corresponded to improvement of the student's lowest scoring skill, and tasked them to engage more fully in their private world, with students reporting on their progress in the final assignment.

I am mindful that the instructional effects of the teaching, social, and cognitive presence I have identified are limited to one subject situated in a specific context (Szeto, 2015). Noting the high percentage of negative impacts to teacher presence (Table 3), the key consideration moving forward is how e-teacher leadership connects with social and 
cognitive presence in the Col instructional approach to contribute meaningful educational experience in future blended and online learning contexts.

With respect to SDT, all three needs were compromised, especially competence (Table 4). The ongoing technological difficulties in how we delivered our content negatively impacted on our sense of mastery over what we were teaching, even though we were both specialists in the discipline, and our mental health as pedagogues suffered as a result. The development of competence is the focus of the subject, and we deliver the subject as, and with, disciplinary experts. What I found interesting was that the experience my colleague and I had as teacher-as-performer was substantially compromised by the technological challenges. Consistent with the Klassen et al. (2012) study, this then compromised our need for relatedness with students by assaulting our engagement and exacerbating negative emotions. Another point of interest is that the students detected and reflected the core need of competence, with $82 \%$ of comments referring to their experience of this need being compromised. In counterpoint, almost every comment under "best aspects" of the subject referred to their recognition of the instructor's competence, despite the technological challenges that I feared would harm our teaching presence leadership (Szeto, 2015).

\subsection{Moving to the Future}

Considering how to refine delivery in the future in either a blended or fully online mode in terms of the SAMR (which stands for substitution, augmentation, modification, and redefinition) model (Puentedura, 2014), I am challenged to move beyond using a hybrid approach simply as a substitution of the way we traditionally taught the subject, where the design, assessment, and communication remained the same and without functional change. Based on student feedback regarding the group assessment task, potential ways of transforming the subject include using the learning management system discussion board to create an ongoing, group assessment task reflecting on key concepts and resources throughout the subject, which forms part of their assessment, augmented by live performance to the group whole subject cohort, and pre-recorded video diary selfreflections on simulated performances. In this way, we can more effectively use opportunities afforded in the online teaching method to modify and redefine the subject.

In closing, I believe that using a hybrid LS/F2F instructional method enabled us to reach our goal in the subject: to help musicians learn to execute the craft of their musicianship uninhibited by negative emotional constraints, with the deep satisfaction and sense of wellbeing that can be experienced when this is done well. Perhaps the most telling evidence of the impression my colleague and I had of the success of this method is our consideration of teaching future iterations of this subject in full F2F format. Rees (2002) asserts two 
factors that repeatedly indicate credibility in the distance learning literature as need and longevity. Need of what we were teaching was evident from students since they requested this subject be mandatory in the performance curriculum (as they had in previous years). Need of how we do this using an online approach seems inevitable as teaching moves to embrace globalized, mobile, and flexible learning modes. Yet for us, the longevity of the hybrid method has been compromised due to our traumatic experience of repeated technical impediments, and hence our decision to return to full F2F delivery mode. The advent of COVID-19 teaching restrictions has now forced us to reimagine the subject with a greater, if not fully, online mode with synchronous and asynchronous instruction. It is with intrigue, hope, and confidence in the rapidly expanding online music instruction knowledge base that we now prepare to enter that new void.

\section{REFERENCES}

Abdous, M. H. \& Yoshimura, M. (2010). Learner outcomes and satisfaction: A comparison of live video-streamed instruction, satellite broadcast instruction, and face-to-face instruction. Computers \& Education, 55(2), 733-741. https://doi.org/10.1016/j.compedu. 2010.03.006

Albert, D. J. (2015). Online versus traditional master of music in music education degree programs: Students' reasons for choosing, Journal of Music Teacher Education, 25(1), 52 -64. https://doi.org/10.1177/1057083714548588

Baard, P. P., Deci, E. L., \& Ryan, R. M. (2004). Intrinsic need satisfaction: A motivational basis of performance and well-being in two work settings, Journal of Applied Social Psychology, 34(10), 2045-2068. https://doi.org/10.1111/j.1559-1816.2004.tb02690.x

Blackburn, A. (2017). Performing online: Approaches to teaching performance studies in higher education within a fully online environment. Australian Journal of Music Education, 51(1), 63-72.

Clandinin, D. J., Pushor, D., \& Orr, A. M. (2007). Navigating sites for narrative inquiry. Journal of Teacher Education, 58(1), 21-35. https://doi.org/ 10.1177/0022487106296218

Evans, P. \& Bonneville-Roussy, A. (2016). Self-determined motivation for practice in university music students, Psychology of Music, 44(5), 1095-1110. https://doi.org/ 10.1177/0305735615610926

Garrison, D. R. (2009). Communities of inquiry in online learning. In P. L. Rogers, G. A. Berg, J. V. Boettcher, C. Howard, L. Justice, \& K. D. Schenk (Eds.), Encyclopedia of distance learning (2nd ed., pp. 352-355). IGI Global. https://doi.org/10.4018/978-1-60566198-8.ch052 
Garrison, D. R., Anderson, T., \& Archer, W. (2000). Critical inquiry in a text-based environment: Computer conferencing in higher education. The Internet and Higher Education, 2(2-3), 87-105. https://doi.org/10.1016/S1096-7516(00)00016-6

Garrison, D. R., Cleveland-Innes, M., \& Fung, T. S. (2010). Exploring causal relationships among teaching, cognitive and social presence: Student perceptions of the community of inquiry framework. The Internet and Higher Education, 13(1-2), 31-36. https://doi.org/ 10.1016/j.iheduc.2009.10.002

Ginsborg, J., Spahn, C., \& Williamon, A. (2012). Health promotion in higher music education. In R. A. R. Macdonald, G. Kreutz, \& L. Mitchell (Eds.), Music, health and wellbeing (pp. 356-366). Oxford University Press.

Goodyear, P. (2015). Teaching as design. HERDSA Review of Higher Education, 2, 27 -50 .

Handler, L. (2011). Live and online: Using co-streaming to reach users. Medical Reference Services Quarterly, 30(2), 120-129. https://doi.org/10.1080/02763869.2011.562773

Harris, K.-L. (2005). Guide for reviewing assessment. Melbourne Center for the Study of Higher Education, The University of Melbourne.

Jang, H., Reeve, J., \& Deci, E. L. (2010). Engaging students in learning activities: It is not autonomy support or structure but autonomy support and structure. Journal of Educational Psychology, 102(3), 588-600. https://doi.org/10.1037/a0019682

Johnson, C. \& Altowairiki, N. (2017). Developing teaching presence in online learning through shared stakeholder responsibility. In P. Vu, S. Frederickson, \& C. Moore (Eds.), Handbook of research on innovative pedagogies and technologies for online learning in higher education (pp. 151-177). IGI Global.

Kegelaers, J. \& Oudejans, R. R. (2020). A process evaluation of a performance psychology intervention for transitioning elite and elite musicians. Frontiers in Psychology, 11, 1090. Retrieved June 6, 2020, from https://www.frontiersin.org/articles/10.3389/ fpsyg.2020.01090/full

Kenny, D. T. \& Ackermann, B. (2016). Optimizing physical and psychological health in performing musicians. In S. Hallam, I. Cross, \& M. Thaut (Eds.), The Oxford handbook of music psychology (2nd ed.). Oxford University Press. Retrieved June 6, 2020, from https://doi.org/10.1093/oxfordhb/9780198722946.013.38

Klassen, R., Perry, N. E., \& Frenzel, A. C. (2012). Teachers' relatedness with students: An underemphasized component of teachers' basic psychological needs. Journal of Educational Psychology, 104(1), 150-165. https://doi.org/10.1037/a0026253

Lowenthal, A. \& Lowenthal, P. R. (2009, April 13-17). Revisiting teaching presence: An analysis of teaching presence across discourse communities [Conference presentation]. 
Annual Meeting of the American Education Research Association, San Diego, CA, United States.

Lowenthal, P. R. \& Parscal, T. (2008). Teaching presence. The Learning Curve, 3(4), 1-4.

McPherson, G. E., Evans, P., Kupers, E., \& Renwick, J. (2016). Applying selfdetermination and self-regulation theories for optimising music performance. In A. Mornell (Ed.), Art in motion III: Performing under pressure (pp. 131-148). Peter Lang.

Mesagno, C., Mornell, A., \& Quinn, A. L. (2016). Choking under pressure in sport and music: Exploring the benefits of theory transfer across domains. In A. Mornell (Ed.), Art in motion III: Performing under pressure (pp. 23-57). Peter Lang.

Nicol, D. J. \& Macfarlane-Dick, D. (2006). Formative assessment and self-regulated learning: A model and seven principles of good feedback practice. Studies in Higher Education, 31(2), 199-218. https://doi.org/10.1080/03075070600572090

Osborne, M. S. \& Franklin, J. (2002). Cognitive processes in music performance anxiety. Australian Journal of Psychology, 54(2), 86-93.

Osborne, M. S., Greene, D., \& Immel, D. (2014). Managing performance anxiety and improving mental skills in conservatoire students through performance psychology training: A pilot study. Psychology of Well-Being, 4(18), 1-17. https://doi.org/10.1186/s13612-0140018-3

Osborne, M. S. \& McPherson, G. E. (2019). Pre-competitive appraisal, performance anxiety and confidence in conservatorium musicians: A case for coping. Psychology of Music, 47(3), 451-462. https://doi.org/10.1177/0305735618755000

Portenga, S. T., Aoyagi, M. W., \& Cohen, A. B. (2017). Helping to build a profession: A working definition of sport and performance psychology. Journal of Sport Psychology in Action, 8(1), 47-59. https://doi.org/10.1080/21520704.2016.1227413

Puentedura, R. R. (2014). SAMR: a contextualised introduction. Retrieved May 25, 2020 , from http://www.hippasus.com/rrpweblog/archives/2014/01/15/

SAMRABriefContextualizedlntroduction.pdf

Rees, F. J. (2002). Distance learning and collaboration in music education. In R. Colwell \& C. Richardson (Eds.), The new handbook of research on music teaching and learning: $A$ project on the music educators national conference (pp. 257-273). Oxford University Press.

Reeves, T. C. (2006). How do you know they are learning?: The importance of alignment in higher education. International Journal of Learning Technology, 2(4), 294-309.

Ruthmann, S. A. \& Hebert, D. G. (2018). Music learning and new media in virtual and online environments. In G. E. McPHerson \& G. F. Welch (Eds.), Creativities, technologies 
and media in music learning and teaching: an Oxford handbook of music education (pp. 254-272). Oxford University Press.

Ryan, R. M. \& Deci, E. L. (2002). An overview of self-determination theory: An organismicdialectical perspective. In E. L. Deci \& R. M. Ryan (Eds.), Handbook of self-determination research (pp. 3-33). University of Rochester Press.

Soffer, T. \& Nachmias, R. (2018). Effectiveness of learning in online academic courses compared with face-to-face courses in higher education. Journal of Computer Assisted Learning, 34(5), 534-543. https://doi.org/10.1111/jcal.12258

Spahn, C., Walther, J.-C., \& Nusseck, M. (2016). The effectiveness of a multimodal concept of audition training for music students in coping with music performance anxiety. Psychology of Music, 44(4), 893-909. https://doi.org/10.1177/0305735615597484

Szeto, E. (2015). Community of inquiry as an instructional approach: What effects of teaching, social and cognitive presences are there in blended synchronous learning and teaching? Computers \& Education, 81, 191-201. https://doi.org/10.1016/j.compedu. 2014.10.015

Taylor, I. M. \& Ntoumanis, N. (2007). Teacher motivational strategies and student selfdetermination in physical education. Journal of Educational Psychology, 99(4), 747-760. https://doi.org/10.1037/0022-0663.99.4.747

U.S. Department of Education. (2010). Evaluation of evidence-based practices in online learning: A meta-analysis and review of online learning studies, Office of Planning, Evaluation, and Policy Development. Retrieved June 6, 2020, from https://www2.ed.gov/rschstat/eval/tech/evidence-based-practices/finalreport.pdf

Watson, D. L. \& Tharp, R. G. (2014). Self-directed behavior: Self-modification for personal adjustment (10th ed.). Wadsworth.

Williamon, A. (Ed.). (2004). Musical excellence: Strategies and techniques to enhance performance. Oxford University Press.

Zimmerman, B. J. (2011). Motivational sources and outcomes of self-regulated learning and performance. In B. J. Zimmerman \& D. H. Schunk (Eds.), Handbook of self-regulation of learning and performance (pp. 49-64). Routledge. 


\section{University Library}

\section{- M M I N E R VA A gateway to Melbourne's research publications}

Minerva Access is the Institutional Repository of The University of Melbourne

Author/s:

Osborne, M

Title:

Entering the live-streaming void and emerging victorious: teaching performance psychology under pressure

Date:

2020

Citation:

Osborne, M. (2020). Entering the live-streaming void and emerging victorious: teaching performance psychology under pressure. International Journal on Innovations in Online Education, 4 (2), pp.1-23. https://doi.org/10.1615/IntJInnovOnlineEdu.2020035052.

Persistent Link:

http://hdl.handle.net/11343/244122 